\title{
HIV infection in Xi'an, China: epidemic characterization, risk factors to false positives and potential utility of the sample-to-cutoff index to identify true positives using Architect HIV Ag/Ab combo
}

\author{
Linchuan Wang ${ }^{1}$, Yao Xiao ${ }^{1}$, Xu-Dong Tian ${ }^{1}$, Jin-xiong Ruan ${ }^{1}$, Wei Chen ${ }^{1}$ and Yan Yu ${ }^{2 *}$
}

\begin{abstract}
Background: In China, although tremendous efforts has been made, the HIV/AIDS is still not controlled.

Objectives: The study was carried out to determine the epidemic of HIV infection in Xi'an, analyse false positives (FP) risk factors and potential utility of sample-to-cutoff index to identify true positives using Architect HIV Ag/Ab Combo.

Methods: A retrospective review for HIV screening by Architect HIV Ag/Ab Combo was performed in a teaching hospital in Xi'an between 2015 and 2016. The prevalence of HIV, positive predictive value (PPV) at different cut-off indexices (COI) were calculated. The epidemic of infections and risk factors for FP results were investigated.

Results: In the study, the HIV prevalence and FP rate of Architect HIV Ag/Ab Combo were 0.076 and 46.08\%, respectively. The Han Chinese, males and people aged < 40 years accounted for the majority of infections (98.29, 76.07 and $73.5 \%$, respectively). $85.47 \%$ of the infections were transmitted through sexual contact (35.04\% of male homosexual and $50.43 \%$ of heterosexual). COI at 1-10, 10-30 and $\geq 30$, the PPVs were 0,50 and $100 \%$, respectively. The independent risk factors for FP, i.e., pregnancy and malignancy had a statistically significant association with FP $(p<0.05)$, and age had a very strong statistically significant association with FP $(p<0.001)$.

Conclusions: In Xi'an, sexual contact was the most important transmission mode for HIV, and the infections were predominantly identified in Han Chinese, males, young and middle-aged people. For Architect HIV Ag/Ab Combo, it can achieve $100 \%$ of PPV with COI $\geq 30$, and the age was strongly statistically associated with FP.
\end{abstract}

Keywords: HIV epidemic, False positives, Architect HIV ag/ab combo

\section{Background}

The transmission of HIV/AIDS in China has undergone entry (1985-1988), expansion (1989-1993) and rapidly increasing phase (1994-present) [1, 2]. Since one AIDS case from an Argentine tourist in Beijing and four HIV infections from hemophiliac patients undergoing treatment with Factor VIII in Zhejiang Province were identified in 1985 [1-4], the spread rate of HIV in China is

\footnotetext{
* Correspondence: yu.yan74@163.com

${ }^{2}$ Inspection Department of Hong-Hui Hospital, Xi'an Jiaotong University College of Medicine, Nan Guo Road No 76, Xi'an, Shaanxi Province, China Full list of author information is available at the end of the article
}

alarming. In 1994, HIV/AIDS cases had been reported in 22 provinces [3], and since 1998, a nation-wide spread had been observed in China [1, 2, 5]. In 2015, 577,423 people were living with HIV/AIDS in mainland China [4, $6]$, and among people aged $>15$ years, more than 5000 new cases had been reported in 9 provinces, and 10005000 new cases had been reported in 14 provinces (Fig. 1) [7]. Although quite a few prevention policies and tremendous efforts for HIV/AIDS transmission have been made and performed in China, i.e., "ban on imported blood products" [2], blood donors must be tested for HIV since 1995 [1], "Action Plan on HIV/AIDS Prevention" 


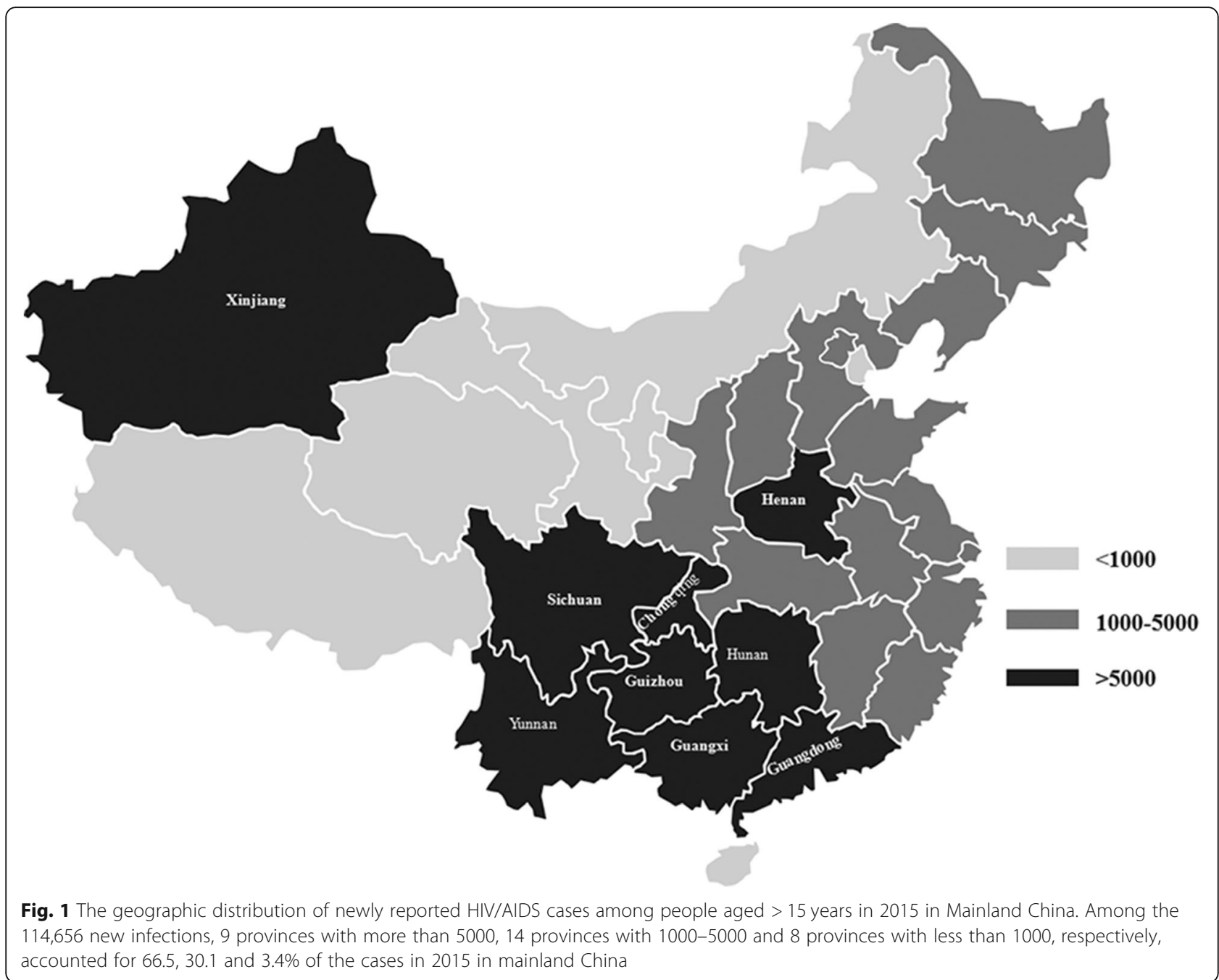

[2, 8], "Methadone Maintenance Treatment (MMT) program" [8-10], and "Four Free One Care" [2, 9], the HIV/AIDS epidemic in China is still not controlled or slowed down.

New and recent HIV infections are more infectious than chronic infections [11-14], thus early identification of HIV infection is crucial to prevent HIV transmission [15]. The algorithm requires a sequence of tests to identify HIV infection for the repeatedly reactive subjects.

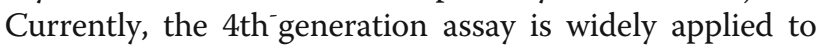
screen HIV in China. Simultaneously detecting the p24 antigen and HIV-1/2 antibodies, the 4 th $^{-}$generation assay is more sensitive than the 3rd-generation assay with approximately 2 weeks window period [16-19]. But nonspecific reactivity [20-24] was often observed because the assay combines two different test principles in one assay. Since the 4th 'generation assay was used as the initial HIV test in our hospital, the incidence of false positives was more frequent than the use of 3rd-generation assay before. HIV false positives may cause inappropriate anxiety to patients or even undesirable consequences. Especially for the sample which was only reactive to the 4th generation assay, we could not differentiate early seroconversion from false-positive.

The present study was carried out to investigate the epidemic of HIV infection in Xi'an, to analyze the positive predictive value (PPV) at different COI, and to identify the risk factors for FP using Architect $\mathrm{HIV} \mathrm{Ag/Ab}$ Combo.

\section{Methods}

\section{Study population}

This study was conducted between January 1, 2015 and October 31, 2016 in the First Affiliated Hospital of Xi'an Jiaotong University, which is the largest hospital in Northwest China. It is a 2541-bed teaching hospital with about 3 millions outpatients annually. During the study period, a total of 154,005 patients underwent HIV screening (77,525 males [50.34\%]; median age 52 years [range:2-89 years]). All repeatedly reactive patients 


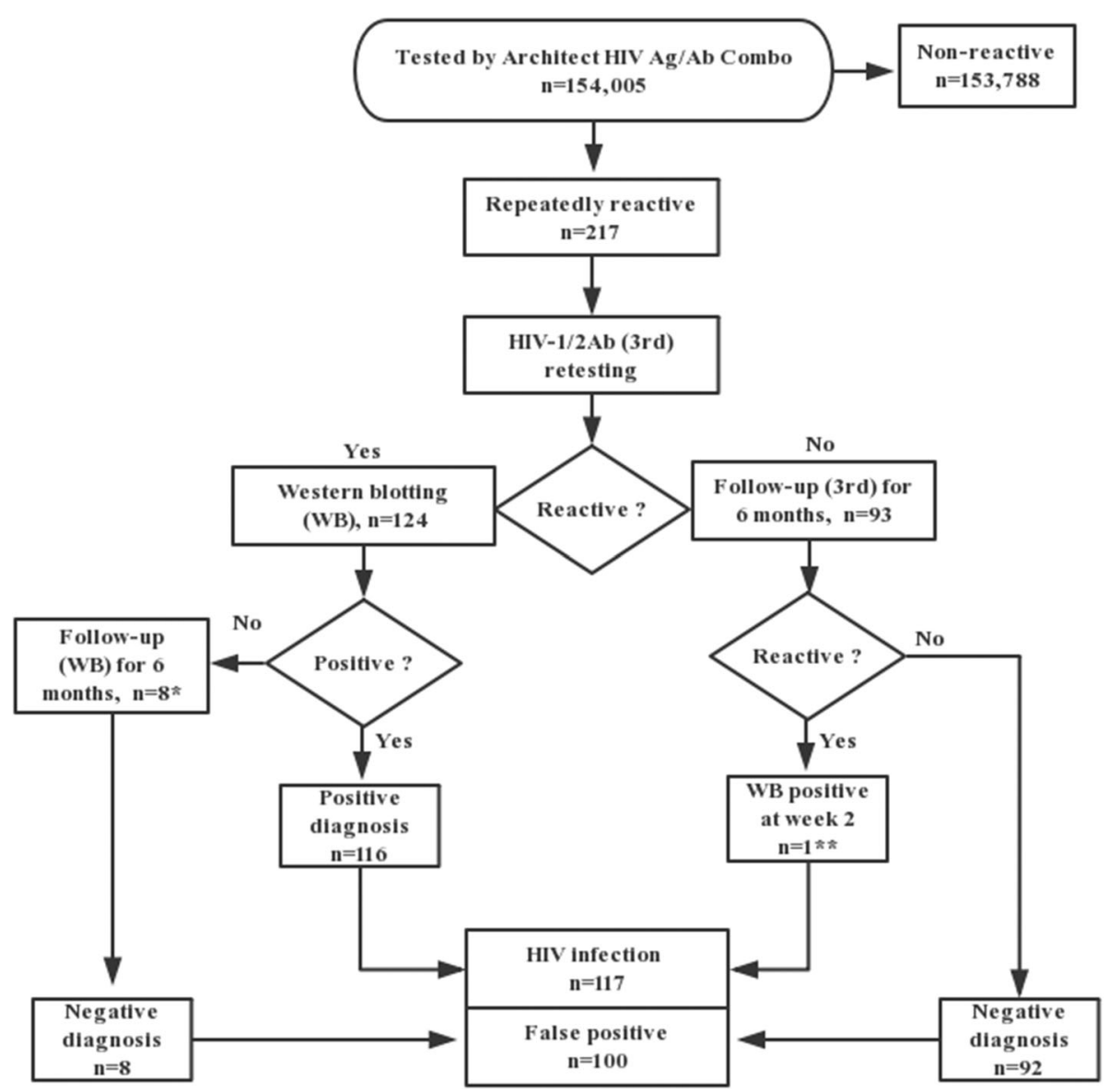

Fig. 2 The flow chart for identifying the $117 \mathrm{HIV}$ infections and 100 false positives. ${ }^{*} 7$ cases were WB negative and one case was WB indeterminate (p24 band). ** one case was reactive to HIV-1/2Ab test and WB positive (gp120/gp160 and p24 bands) at the 2nd week of follow-up

were included in the study. The data in the study were available from the LIS and HIS of the First Affiliated Hospital of Xi'an Jiaotong University and Xi'an, Center for Disease Control and Prevention (CDC), Shaanxi Province, China.

\section{The flow chart for identifying HIV infection}

A 4th generation kit, Architect HIV Ag/Ab Combo (Abbott Diagnostics, Abbott Park, IL) and a 3rd-generation EIA kit, XinChuang HIV-1/2Ab (InTec, INC, XiaMen, FuJian, China) were used as the first and retesting assays, respectively. $\mathrm{COI}$ or $\mathrm{S} / \mathrm{CO} \geq 1$ was defined as reactive, and $\mathrm{COI}$ or $\mathrm{S} / \mathrm{CO}<1$ was defined as non-.reactive.

According to the Chinese CDC guideline, the ID card and telephone should be recorded in the "REPORT OF HIV SCREENING TESTING" and send one copy to the CDC if the result of individual is repeatedly reactive to screening test, and the specimen should be submitted for confirmation (WB, nucleic acid or p24 antigen tests). If the confirmatory test is not positive, follow-up at the 1st, 3rd and 6th month is required to exclude HIV infection. Currently, the nucleic acid and p24 antigen tests are not applied at CDC in Xi'an for HIV confirmation. Thus, for the repeatedly reactive subjects by HIV Ag/Ab Combo, the identifying algorithm used in our hospital was-WB should be conducted if it was also reactive to HIV-1/2Ab. For the only HIV Ag/Ab Combo-reactive subjects, we contacted them through the recorded telephone at the 2nd, 4th week, 3rd and 6th month to carry out HIV-1/2Ab test. Once HIV-1/2Ab was reactive, then WB should be performed. If the initial WB was negative or indeterminate, the subjects were required to perform four WB tests (at week 2, week 4, month 3 and month 6) by Xi'an CDC.

\section{Western blotting}

Western blotting HIV1/2 BLOT 2.2 (MP Biomedicals, Singapore) was conducted at the Xi'an CDC. The WB results were interpreted according to the Chinese CDC criteria: Positive - the presence of at least two bands, including two env bands, or one env band plus one gag band; Indeterminate-reactivity to any of the bands but not compatible with the criteria for a positive interpretation; Negative-the absence of any of the specific bands. 
Table 1 Characteristics of true-positive and false-positive population

\begin{tabular}{|c|c|c|c|}
\hline Characteristics & $\begin{array}{l}\text { TP population } \\
n=117\end{array}$ & $\begin{array}{l}\text { FP population } \\
n=100\end{array}$ & $p$-value \\
\hline \multicolumn{4}{|l|}{ Sex } \\
\hline Male & $89(76.07 \%)$ & $61(61 \%)$ & 0.019 \\
\hline Female & $28(23.93 \%)$ & $39(39 \%)$ & \\
\hline $\begin{array}{l}\text { Age, median (IQR), } \\
\text { years }\end{array}$ & $30(26-41)$ & $\begin{array}{l}52.5 \\
(45-63.5)\end{array}$ & 0.000 \\
\hline-40 & $86(73.5 \%)$ & $20(20 \%)$ & 0.000 \\
\hline $40-60$ & $27(23.08 \%)$ & 31 (31\%) & 0.219 \\
\hline$\geq 60$ & $4(3.42 \%)$ & $49(49 \%)$ & 0.000 \\
\hline \multicolumn{4}{|l|}{ Ethnicity } \\
\hline Han & 115 (98.29\%) & 99 (99\%) & $>0.05$ \\
\hline Minority & $2(1.71 \%)$ & 1 & \\
\hline \multicolumn{4}{|l|}{ Source of patients } \\
\hline Outpatients & $106(90.6 \%)$ & $9(9 \%)$ & 0.000 \\
\hline $\begin{array}{l}\text { Hospitalized } \\
\text { patients }\end{array}$ & $11(9.4 \%)$ & 91 (91\%) & \\
\hline \multicolumn{4}{|l|}{ Marital status } \\
\hline Unmarried & $52(44.44 \%)$ & $8(8 \%)$ & 0.000 \\
\hline Married & $65(55.56 \%)$ & $92(92 \%)$ & \\
\hline \multicolumn{4}{|l|}{ Transmission modes } \\
\hline $\begin{array}{l}\text { Male homosexual } \\
\text { contact }\end{array}$ & $41(35.04 \%)$ & / & \\
\hline $\begin{array}{l}\text { Heterosexual } \\
\text { contact }\end{array}$ & $59(50.43 \%)$ & / & \\
\hline Injecting drug & $6(5.13 \%)$ & / & \\
\hline Unknown & $11(9.4 \%)$ & / & \\
\hline \multicolumn{4}{|l|}{ Job } \\
\hline College students & $22(18.8 \%)$ & / & \\
\hline $\begin{array}{l}\text { Unemployed/ } \\
\text { informal employees }\end{array}$ & $34(29.06 \%)$ & / & \\
\hline Formal employees & $50(42.74 \%)$ & / & \\
\hline Peasants & $2(1.71 \%)$ & / & \\
\hline Unknown & $9(7.69 \%)$ & / & \\
\hline COI, median (IQR) & $\begin{array}{l}470.53 \\
(273.99-628.21)\end{array}$ & $\begin{array}{l}3.21 \\
(1.82-8.58)\end{array}$ & 0.000 \\
\hline \multicolumn{4}{|l|}{ Clinical symptoms } \\
\hline \multicolumn{4}{|l|}{ Flu-like } \\
\hline Fever & 12 & 1 & \\
\hline $\begin{array}{l}\text { Painful pharynx } \\
\text { and larynx }\end{array}$ & 2 & 0 & \\
\hline Swelling of tonsil & 4 & 0 & \\
\hline $\begin{array}{l}\text { Swelling of } \\
\text { lymph nodes }\end{array}$ & 5 & 0 & \\
\hline Total & $23(19.66 \%)$ & $1(1 \%)$ & 0.000 \\
\hline \multicolumn{4}{|l|}{ Skin diseases } \\
\hline Rashes & 6 & 1 & \\
\hline
\end{tabular}

Table 1 Characteristics of true-positive and false-positive population (Continued)

\begin{tabular}{llll}
\hline Characteristics & $\begin{array}{l}\text { TP population } \\
n=117\end{array}$ & $\begin{array}{l}\text { FP population } \\
n=100\end{array}$ & $p$-value \\
\hline Genital herpes & 4 & 0 & \\
Genital condyloma & 4 & 0 & \\
Perianal condyloma & 3 & 0 & \\
Perianal abscess & 10 & 0 & 0.000 \\
Total & $27(23.08 \%)$ & $1(1 \%)$ & \\
& & & \\
\hline
\end{tabular}

\section{Statistical analysis}

Statistical analyses were performed by SPSS13.0 (serial number 5026743; SPSS Inc., Chicago, Illinois, USA), and WB positive was the standard for HIV infection diagnosis in the study. The Mann-Whitney U-test was used for continuous variables (medians of the age and COI) comparison of between true-positive (TP) and false-positive (FP) patients, because they were not normal distribution. Categorical variables were compared using the Fisher's exact test. The risk factors of false positives were evaluated using logistic regression analysis. A $p$-value $<0.05$ was considered to be statistically significant.

\section{Results}

Epidemic of true-positive and false-positive populations During the study period, a total of 217 patients who were repeatedly reactive by ARCHITECT HIV Ag/Ab Combo were included. Among them, HIV-1/2Ab reactive and non-reactive numbers were 124 and 93 . According to the identifying algorithm used in our hospital, 116 and 8 of the 124 cases were diagnosed as positive by the initial WB and negative by four follow-up WB tests, respectively. For the 93 cases with only HIV Ag/Ab Combo reactive results, 92 cases were non-reactive to four followup tests by $\mathrm{HIV}-1 / 2 \mathrm{Ab}$ assay, one case was reactive to HIV-1/2Ab assay and WB positive (gp120/gp160 and p24 bands) at the 2nd week of follow-up. Overall, according to the results of WB and six months follow-up, 117 and 100 of the 217 cases were classified as TP and FP for HIV infection, respectively, Fig. 2 . The median age of the FP population was 52.5 years (range $20-84$ years; males [ $n=$ 61]; females $[n=39])$. The Han Chinese, hospitalized patients and married cases accounted for the majority of the FP population $(99,91$ and $92 \%$, respectively). The distributions of $<40,40-60$ and $\geq 60$ years for the FP population were 20, 31 and 49\%, respectively, Table 1 .

The TP population comprised 89 males and 28 females with a median age of 30 years (range: $17-72$ years). Hans Chinese, outpatients and married cases accounted for the majority of infections (98.29, 90.6 and 55.56\%, respectively). The constituent ratios of the transmission modes were $85.47 \%$ for sexual contact (male homosexual contact, $35.04 \%$; heterosexual contact, $50.43 \%$ ), $5.13 \%$ for injecting 

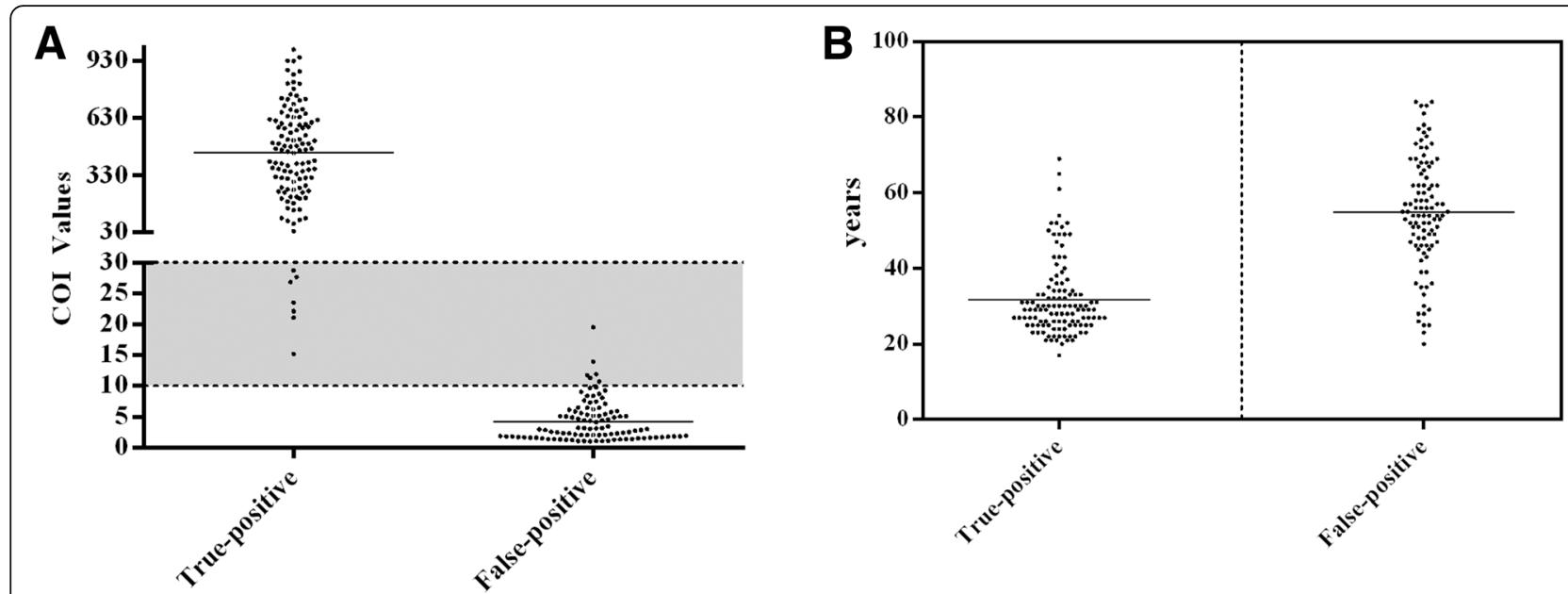

Fig. 3 The comparison between HIV true-positive and false-positive group of $\mathbf{a}$ the COI values and $\mathbf{b}$ age

drug and 9.4\% for unknown. Among the infections, one juveniles case ( 17 years) and 6 older cases ( $\geq 60$ years) were observed. The age-specific distributions of infections were $73.5 \%$ for $<40$ years, $23.08 \%$ for $40-60$ years and $3.42 \%$ for $\geq 60$ years. Of the 117 infections, $22(18.8 \%)$ were college students, $34(29.06 \%)$ were unemployed/informal employees, $50(42.74 \%)$ were formal employees, $2(1.71 \%)$ were peasants and $9(7.69 \%)$ were unknown, Table 1.

Compared to the FP population, the TP population was more likely to be younger ( 30 vs $52.5, p=0.000$ ), unmarried $(44.44 \%$ vs $8 \%, p=0.000)$ and from outpatient $(90.6 \%$ vs $9 \%, p=0.000)$. The proportion of males in the TP population was significantly higher than that in the FP population $(76.07 \%$ vs $61 \%, p=0.019)$. Flu-like clinical symptoms $(n=23)$ and skin diseases $(n=27)$ were presented in $42.74 \%(50 / 117)$ of the TP patients, i.e., fever $(n=12)$, painful pharynx and larynx $(n=2)$, swelling of the tonsils $(n=4)$ and lymph nodes $(n=5)$, rashes $(n=6)$, genital herpes $(n=4)$ and condyloma $(n=4)$, perianal condyloma $(n=3)$ and abscess $(n=10)$, Table 1.

\section{Consistency and PPV at different $\mathrm{COI}$ values}

Of the 217 repeatedly reactive subjects, the COI for the FP population was significantly lower than that for the TP population (3.21 vs $470.53, p=0.000$ ), (Fig. 3a and Table 1). They were divided into low ( $\mathrm{L}: 1 \leq \mathrm{COI}<10)$, medium
(M: $10 \leq \mathrm{COI}<30)$ and high $(\mathrm{H}: \mathrm{COI} \geq 30)$ groups. In the L group (range, 1.01-9.71), only 2 of 93 cases were reactive to HIV-1/2Ab retesting, and all of the 93 cases were classified as FP. In the M group (range, 10.72-27.66), 12 of 14 cases were retest-reactive to HIV-1/2Ab and 6 cases were WB positive, but one case who was only 4th generation-reactive had seroconversion for HIV-1/2Ab and WB at the 2nd week of follow-up. All of the 110 cases in the $\mathrm{H}$ group (range, 37.65-1049.84) were HIV-1/2Ab reactive and WB positive. Overall, consistency (4th generation and HIV-1/2Ab assays) and PPV were $2.15 \%$ and 0 for the $\mathrm{L}$ group, 85.71 and $50 \%$ for the $M$ group and $100,100 \%$ for the $\mathrm{H}$ group, respectively. In total, 116 of 124 cases with consistent results (reactive to both 4th generation and HIV-1/2Ab assays) were TP (PPV: 93.55\%), and 1 of 93 with inconsistent result (only reactive to 4th generation assay) was TP (PPV: 1.08\%), Table 2.

\section{Analysis of risk factors for HIV false positives}

In our study populations, the prevalence of HIV was 0.076\% (117/154,005). Although the ARCHITECT HIV $\mathrm{Ag} / \mathrm{Ab}$ Combo had a specificity of 99.94\% (153,788/ 153888) for HIV diagnosis, in fact, of the 217 repeatedly reactive subjects by the assay, the FP rate was $46.08 \%$ (100/217). The FP patients were significantly older than the TP patients, $(52.5$ vs $30, p=0.000)$, Fig. $3 \mathrm{~b}$. With

Table 2 Consistency and PPV at different COI values for HIV screening

\begin{tabular}{|c|c|c|c|c|c|}
\hline \multicolumn{2}{|c|}{ First-test-reactive (Ag/Ab Combo) } & \multicolumn{3}{|c|}{ Retesting by 3rd-generation } & \multirow{2}{*}{$\begin{array}{l}\text { PPV } \\
\text { (\%) }\end{array}$} \\
\hline Groups (COI Values) & No. & Reactive (TP) & Non-reactive (TP) & Consistency(\%) & \\
\hline$L(1.00-10.00)$ & 93 & $2(0)$ & $91(0)$ & 2.15 & 0 \\
\hline M (10.00-30.00) & 14 & $12(6)$ & $2(1)$ & 85.71 & 50 \\
\hline$H(\geq 30.00)$ & 110 & $110(110)$ & 0 & 100 & 100 \\
\hline Total & 217 & $124(116)$ & $93(1)$ & 57.14 & 53.92 \\
\hline
\end{tabular}

Note: TP was true positive 


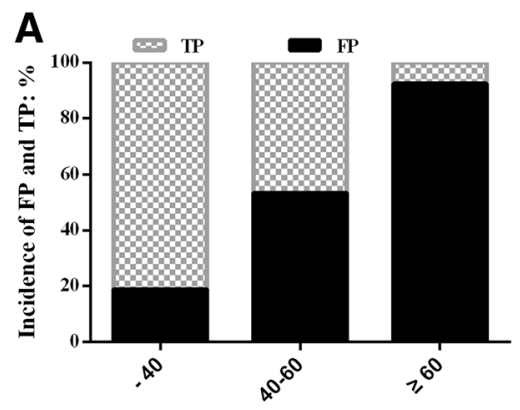

Age (years)

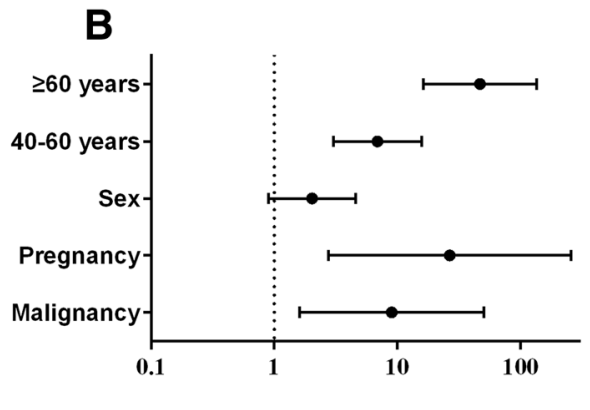

Adjusted Odds ratio

Fig. 4 The incidence of TP and FP at age-specific distributions for repeatedly reactive subjects (a), and (b) the adjusted odds ratio and $95 \%$ confidence intervals of risk factors for FP by multivariate analysis

Table 3 Binary Logistic Analysis for the risk factors of HIV false positives

\begin{tabular}{|c|c|c|c|c|c|c|c|c|}
\hline \multirow[t]{2}{*}{ Characteristics } & \multicolumn{2}{|c|}{ False-positive } & \multicolumn{3}{|l|}{ Crude } & \multicolumn{3}{|c|}{ Adjusted } \\
\hline & Yes & No & $\mathrm{OR}$ & $95 \% \mathrm{Cl}$ & $p$-value & $\mathrm{OR}$ & $95 \% \mathrm{Cl}$ & $p$-value \\
\hline \multicolumn{9}{|l|}{ Sex } \\
\hline Male & 61 & 89 & 1 & & & 1 & & \\
\hline Female & 39 & 28 & 2.03 & $1.13-3.65$ & $0.017^{*}$ & 2.03 & $0.9-4.57$ & 0.09 \\
\hline \multicolumn{9}{|l|}{ Age, years } \\
\hline-40 & 20 & 86 & 1 & & & 1 & & \\
\hline $40-60$ & 31 & 27 & 5.44 & $2.64-11.22$ & 0.000 & 6.9 & $3.02-15.78$ & $0.000^{* * *}$ \\
\hline$\geq 60$ & 49 & 4 & 36.25 & $13.65-96.24$ & 0.000 & 46.85 & $16.28-134.81$ & $0.000^{* * *}$ \\
\hline \multicolumn{9}{|l|}{ Ethnicity } \\
\hline Han & 99 & 115 & 1 & & & 1 & & \\
\hline Minority & 1 & 2 & 1.72 & $0.15-19.28$ & 0.659 & 0.71 & $0.06-9.09$ & 0.794 \\
\hline \multicolumn{9}{|l|}{ Comorbidity } \\
\hline \multicolumn{9}{|c|}{ Renal diseases } \\
\hline No & 95 & 115 & 1 & & & 1 & & \\
\hline Yes & 5 & 2 & 3.03 & $0.57-15.95$ & 0.192 & 1.47 & $0.13-17.28$ & 0.761 \\
\hline \multicolumn{9}{|c|}{ HBV infection } \\
\hline No & 95 & 98 & 1 & & & 1 & & \\
\hline Yes & 5 & 2 & 3.03 & $0.57-15.95$ & 0.192 & 1.77 & $0.13-24.56$ & 0.670 \\
\hline \multicolumn{9}{|l|}{ Malignancy } \\
\hline No & 83 & 115 & 1 & & & 1 & & \\
\hline Yes & 17 & 2 & 11.78 & $2.65-52.37$ & $0.001^{* * *}$ & 9 & $1.61-50.4$ & $0.012^{*}$ \\
\hline \multicolumn{9}{|l|}{ Pregnancy } \\
\hline No & 94 & 116 & 1 & & & 1 & & \\
\hline Yes & 6 & 1 & 6.11 & $0.70-53.16$ & 0.101 & 26.58 & $2.75-256.6$ & $0.005^{*}$ \\
\hline \multicolumn{9}{|c|}{ Autoimmune diseases } \\
\hline No & 98 & 117 & 1 & & & 1 & & \\
\hline Yes & 2 & 0 & 4.83 & $0.53-43.97$ & 0.162 & 9.35 & $0.57-152.74$ & 0.117 \\
\hline
\end{tabular}


increased age, the incidence of TP decreased, but that of FP increased, Fig. 4a.

Univariable analysis showed that the sex, age, malignancy and pregnancy were significantly associated with FP, $P<0.05$. Multivariable analysis was conducted to control for the effects of confounding variables. In this analysis, a dependent variable was defined as the presence of FP and independent variables were intrinsic factors, i.e., sex, age, ethnicity and comorbidity. The final logistic regression analysis showed that age, malignancy and pregnancy were independent risk factors for FP. Among the risk factors, malignancy and pregnancy had a statistically significant association with FP $(p<0.05)$, and the age ( $\geq 40$ years) had a very strong statistically significant association with FP $(p<0.001)$. Patients who were malignancy, pregnancy, at $40-60$ and $\geq 60$ years were 9, 26.58, 6.9 and 46.85 times, respectively, more likely to be tested as FP compared to the control patients (Table 3 and Fig. 4b).

\section{Discussion}

The prevalence of HIV in our study populations was $0.076 \%$, which was close to other studies in China [2527]. Men who have sex with men (MSM), female sex workers (FSWs) and injecting drug users (IDUs) are the three most-at-risk populations in China [10]. With the effective implementation of needle exchange ${ }^{2}$ and MMT programs [8-10, 28], now, sexual contact especially through MSM has become the very significant transmission mode in China $[29,30]$. In our study, the main characteristics for the HIV infection epidemic in Xi'an were: (i) sexual contact as the predominant transmission mode, with MSM and heterosexual transmission accounting for 35.04 and $50.43 \%$, respectively of the cases; (ii) the majority of infections were Han Chinese (98.29\%) and aged < 40 years $(73.5 \%$ ), and; (iii) the HIV-infected population has recently shifted from the at-risk population to the general population. Among the 117 infections in the study, one case was 17 years old, 6 cases were $\geq$ 60 years, and 14 infections were college students.

Previous reports $[21,22]$ have indicated that the PPV of 4th-generation assay was poor. In our study, although it seemed that the specificity (99.94\%) of ARCHITECT HIV Ag/Ab Combo was excellent and was also consistent with other reports $[31,32]$. Moreover, of the 217 repeatedly reactive cases by the assay, $46.08 \%$ were found to be FP. We found that the FP rate decreased as the test values increased $[14,33]$. For ARCHITECT HIV Ag/ $\mathrm{Ab}$ Combo, the FP rate was $100 \%$ at $1-10$ of COI, but the FP rate decreased to 0 when the COI was $\geq 30$. A variety of intrinsic factors for $\mathrm{FP}$ were investigated in the study. Univariable analysis showed that sex, age, malignancy and pregnancy were significantly associated with FP $(p<0.05)$. Multivariable analysis indicated that age, malignancy and pregnancy were the independent risk factors for FP. There was a statistically significant association for malignancy and pregnancy with $\mathrm{FP}(p<0.05)$, and a very strong statistically significant association for age with FP $(p<0.001)$. Patients aged $\geq 60$ years are 46.85 times more likely to be tested as FP compared to the control patients ( $<40$ years).

If test results are repeatedly reactive to the 4th-generation assay, a WB should be performed in according with the routine algorithm of the CDC guideline, and specimen with WB negative or indeterminate result should undergo nucleic acid testing (NAT). However, NAT and p24 antigen tests are not currently applied at the CDC and hospitals in Xi'an for the diagnosis of HIV infection. Considering that WB is a confirmatory test, a WB-negative result is often regarded as exclusion of HIV infection by the patient and clinician in China, and the incorrect understand and treatment could likely lead to serious consequences for the early infections. In theory, only 4th-generation-reactive implies that the antibodies to HIV are absent or insufficient in the blood, and a subsequent WB is not essential. Thus, a 4th-generation assay as the first test to shorten the window period, a 3rd-generation retesting for HIV-1/2Ab as the supplemental test to determine performing WB or not, and the follow-up protocols to shorten diagnosis of HIV infection and exclude HIV infection were used in our hospital. In the study, if WB was conducted for the 93 cases who were only reactive to HIV Ag/Ab Combo, they may be tested as WB negative. Although 92 of the cases were FP, one case had seroconversion at the 2nd week of follow-up.

\section{Conclusions}

In the study, the HIV infection epidemic and the shortcomings of the current HIV testing algorithm used in Xi'an, China, were investigated and the potential utility of the sample-to-cutoff index to discriminate FP from TP was conducted. Overall, in Xi'an, sexual contact was the most important mode for HIV transmission, and the infections were predominantly found in Han Chinese, males, young and middle-aged people. The HIV-infected population has recently shifted from the at-risk population to the general population. HIV infection in juveniles, older people and college students should be more concerned. With regard to the Architect HIV Ag/Ab Combo, COI at $1-10$ and $\geq 30$ can be used as a reliable value for FP and TP, respectively, and being aged $\geq 60$ years was the most significant risk factor for FP.

\section{Abbreviations}

AIDS: Acquired Immune Deficiency Syndrome; CDC: Center for Disease Control and Prevention; COl: Cutoff index; FP: False positives; FSWs: Female sex workers; HIV: Human immunodeficiency virus; IDUs: Injecting drug users; 
MMT: Methadone Maintenance Treatment; MSM: Men who have sex with men; TP: True positives; WB: Western blotting

\section{Acknowledgments}

The authors would like to thank Hai-Chao Zheng from Xi'an CDC, Shaanxi, China for his contribution of the data collection in the study.

\section{Funding}

This study was supported by the grant of The First Affiliated Hospital of Xi'an Jiaotong University, Shaanxi Province, China (No. 2016MS-01).

\section{Availability of data and materials}

The data used in the study was available from Xi'an CDC and LIS and HIS of the First Affiliated Hospital of Xi'an Jiaotong University.

\section{Authors' contributions}

LW and YY were major contributors in the writing of the manuscript. LW and WC were responsible for the study design. The statistical analysis and figure of the study were performed by LW, YX, XDT, JR, and YY. All authors read and approved the final manuscript.

\section{Ethics approval and consent to participate}

The study was deemed exempt from review by the Ethics Committee of the First Affiliated Hospital of Xi'an Jiaotong University as routine data for clinical purposes were used, and all patient information remained confidential in the study.

\section{Consent for publication}

$L W, Y X, X D T, J R, Y Y$ and WC have read and approved the final manuscript for publication in Antimicrobial Resistance \& Infection Control.

\section{Competing interests}

LW, YX, XDT, JR, YY and WC declare that they have no competing interest.

\section{Publisher's Note}

Springer Nature remains neutral with regard to jurisdictional claims in published maps and institutional affiliations.

\section{Author details}

${ }^{1}$ Clinical Laboratory of the First Affiliated Hospital of Xi'an Jiaotong University, Yan Ta Road No 277, Xi'an, Shaanxi Province, China. ${ }^{2}$ Inspection Department of Hong-Hui Hospital, Xi'an Jiaotong University College of Medicine, Nan Guo Road No 76, Xi'an, Shaanxi Province, China.

\section{Received: 15 December 2017 Accepted: 3 January 2019}

\section{Published online: 11 January 2019}

\section{References}

1. Zeng Y, Wu Z. Control of Aids Epidemic in China. Bulletin of the Chinese Academy of Sciences. 2000;2(14):106-11.

2. Wu Z, Sullivan SG, Wang Y, Rotheram-Borus MJ, Detels R. Evolution of China's response to HIV/AIDS. Lancet. 2007;369:679-90.

3. Yu ES, Xie Q, Zhang K, Lu P, Chan LL. HIV infection and AIDS in China, 1985 through 1994. Am J Public Health. 1996;86:1116.

4. Yan Y, Wu S, Chen L, Yan P, Qiu Y, Xie M, et al. Shift in HIV/AIDS epidemic in southeastern China: a longitudinal study from 1987 to 2015. Int J Environ Res Public Health. 2016;13:794.

5. Kaufman J, Jing J. China and AIDS--the time to act is now. Science. 2002;296:2339.

6. National Center for AIDS/STD Control and Prevention. Update on the AIDS/ STD epidemic in China and main response in control and prevention in December 2015. Chin J AIDS/STD. 2016;22(2):69 In Chinese.

7. Wang L, Qin Q, Ding Z, Cai C, Guo W, Li D, et al. Current situation of AIDS epidemic in China. Chin J AIDS/STD. 2017;23(4):330-3 (In Chinese).

8. Rou K, Sullivan SG, Peng L, Wu Z. Scaling up prevention programmes to reduce the sexual transmission of HIV in China. Int J Epidemiol. 2010; 39(Suppl 2):ii38.

9. Wu Z, Wang Y, Detels R, Rotheramborus MJ. China AIDS policy implementation: reversing the HIV/AIDS epidemic by 2015. Int J Epidemiol. 2010;39(Suppl 2):ii1.

10. Yi H, Lau JTF, Yi H, Lau JTF. Emerging issues, challenges and aspirations in the HIV/AIDS epidemic in China. Public Health. 2011;125:257-9.
11. Shaw GM, Hunter E. HIV transmission. Cold Spring Harb Perspect Med. 2012; 2(11):705-9.

12. Stekler J, Maenza J, Stevens CE, Swenson PD, Coombs RW, Wood RW, et al. Screening for acute HIV infection: lessons learned. Clin Infect Dis. 2007; 44(3):459-61.

13. Wawer MJ, Gray RH, Sewankambo NK, Serwadda D, Li X, Laeyendecker O, et al. Rates of HIV-1 transmission per coital act, by stage of HIV-1 infection, in Rakai, Uganda. J Infect Dis. 2005;191(9):1403-9.

14. Wang L, Zhou KH, Zhao HP, Wang JH, Zheng HC, et al. The characteristics of screening and confirmatory test results for HIV in Xi'an, China. Plos One. 2017;12(7):e0180071

15. Li X, Yue W, Ren X, Deng S, Hu G, Yu S, et al. Characterization of humoral immune responses against capsid protein p24 and transmembrane glycoprotein gp41 of human immunodeficiency virus type 1 in China. PLoS One. 2016:11:e0165874.

16. Mitchell EO, Stewart G, Bajzik O, Ferret M, Bentsen C, Shriver MK. Performance comparison of the 4th generation bio-rad laboratories GS HIV combo Ag/Ab EIA on the EVOLIS ${ }^{\mathrm{TM}}$ automated system versus Abbott ARCHITECT HIV Ag/Ab combo, Ortho anti-HIV $1+2$ EIA on Vitros ECi and Siemens HIV-1/O/2 enhanced on Advia centaur. J Clin Virol. 2013:58:79-84.

17. Lee K, Park HD, Kang ES. Reduction of the HIV seroconversion window period and false positive rate by using ADVIA centaur HIV antigen/antibody combo assay. Ann Lab Med. 2013;33:420-5.

18. Weber B, Fall EH, Berger A, Doerr HW. Reduction of diagnostic window by new fourth-generation human immunodeficiency virus screening assays. J Clin Microbiol. 1998;36:2235-9.

19. Pandori MW, Hackett J, Louie B, Vallari A, Dowling T, Liska S, et al. Assessment of the ability of a fourth-generation immunoassay for human immunodeficiency virus (HIV) antibody and p24 antigen to detect both acute and recent HIV infections in a high-risk setting. J Clin Microbiol. 2009;47:2639-42.

20. Erickson CP, Mcniff T, Klausner JD. Influenza vaccination and false positive HIV results. N Engl J Med. 2006;354(13):1422-3.

21. Everett DB, Weiss HA, Changalucha J, Anemona A, Chirwa T, Ross DA, et al. Low specificity of the murex fourth-generation HIV enzyme immunoassay in Tanzanian adolescents. Tropical Med Int Health. 2010; 12(11):1323-6.

22. Kim S, Lee JH, Choi JY, Kim JM, Kim HS. False-positive rate of a "fourthgeneration" HIV antigen/antibody combination assay in an area of low HIV prevalence. Clin Vaccine Immunol. 2010;17(10):46.

23. Mahajan VS, Pace CA, Jarolim P. Interpretation of HIV serologic testing results. Clin Chem. 2010;56(10):1523-6.

24. Shimasano T, Yamada R, Sekita K, Hankins RW, Hori H, Seto H, et al. A human immunodeficiency virus screening algorithm to address the high rate of false-positive results in pregnant women in Japan. PLoS One. 2009;5(2):e9382.

25. Xu S, Wang Q, Zhang W, Qiu Z, Cui J, Yan W, et al. Seroprevalence of the hepatitis $B$, hepatitis $C$, and human immunodeficiency viruses and Treponema pallidum at the Beijing general hospital from 2010 to 2014: a cross-sectional study. PLoS One. 2015;10:e0140854.

26. Xu HF, Zhou HZ, Jiang LX, Zhang N, Zhang X, Guan XR. Trends in HIV infection in the first affiliated Hospital of Harbin China. BMC Infect Dis. 2014;14:1-6.

27. Huang MB, Ye L, Liang BY, Ning CY, Roth WW, Jiang JJ, et al. Characterizing the HIV/AIDS epidemic in the United States and China. Int J Environ Res Public Health. 2016;13(1):30.

28. Yin W, Yang H, Sun X, Gong X, Fang L, Li J, et al. Scaling up the national methadone maintenance treatment program in China: achievements and challenges. Int J Epidemiol. 2010;39(Suppl 2):ii29.

29. Wu J, Meng $Z$, Xu J, Lei $Y$, Jin L, Zhong $P$, et al. New emerging recombinant HIV-1 strains and close transmission linkage of HIV-1 strains in the Chinese MSM population indicate a new epidemic risk. PLoS One. 2013;8:e54322.

30. Xu J, Han X, Reilly KH, Hong S. New features of the HIV epidemic among men who have sex with men in China. Emerg Microbes Infect. 2013;2:e45 MSM.

31. Ly TD, Laperche S, Brennan C, Vallari A, Ebel A, Hunt J, et al. Evaluation of the sensitivity and specificity of six HIV combined p24 antigen and antibody assays. J Virol Methods. 2004;122:185-94.

32. Bentsen C, Mclaughlin L, Mitchell E, Ferrera C, Liska S, Myers R, et al. Performance evaluation of the bio-rad laboratories GS HIV combo ag/ab 
EIA, a 4th generation HIV assay for the simultaneous detection of HIV p24 antigen and antibodies to HIV-1 (groups M and O) and HIV-2 in human serum or plasma. J Clin Virol. 2011;52:S57-61.

33. Chacón L, Mateos ML, Holguín Á. Relevance of cutoff on a 4th generation ELISA performance in the false positive rate during HIV diagnostic in a low HIV prevalence setting. J Clin Virol. 2017;92:11.

Ready to submit your research? Choose BMC and benefit from:

- fast, convenient online submission

- thorough peer review by experienced researchers in your field

- rapid publication on acceptance

- support for research data, including large and complex data types

- gold Open Access which fosters wider collaboration and increased citations

- maximum visibility for your research: over $100 \mathrm{M}$ website views per year

At $\mathrm{BMC}$, research is always in progress.

Learn more biomedcentral.com/submissions 